\title{
A catalytic highly enantioselective direct synthesis of 2-bromo-2-nitroalkan-1-ols through a Henry reaction $\dagger$
}

\author{
Gonzalo Blay,* Victor Hernández-Olmos and José R. Pedro* \\ Received (in Cambridge, UK) 10th June 2008, Accepted 10th July 2008 \\ First published as an Advance Article on the web 29th August 2008 \\ DOI: $10.1039 / \mathbf{b 8 0 9 7 3 9 a}$
}

Highly enantiomerically enriched 2-bromo-2-nitroalkan-1-ols are prepared by direct condensation of aliphatic and aromatic aldehydes with bromonitromethane in the presence of a catalytic amount of copper(II) acetate and a $C_{1}$-symmetric camphorderived amino pyridine ligand.

The reaction between a nitroalkane and a carbonyl compound, the so called Henry or nitro-aldol reaction, provides $\beta$-hydroxy nitroalkanes that are valuable intermediates for the synthesis of polyfunctionalized molecules and biologically active compounds. ${ }^{1}$ In the last years, a number of catalytic enantioselective procedures for this reaction have been developed, most of them involving aldehydes and nitromethane $^{2}$ or, to a lesser extent, other unfunctionalized nitroalkanes. ${ }^{3}$ However, the use of functionalized nitroalkanes has been little studied. The addition of bromonitromethane to a carbonyl compound appears as an attractive method to prepare 2-bromo-2-nitroalkan-1-ols. This kind of compound shows activity against bacteria ${ }^{4}$ and other microorganisms, such as algae and fungi, and hence they are used as industrial microbicides $^{5}$ in oil and gas wells, ${ }^{6}$ paper manufacture, ${ }^{7}$ fertilizers, ${ }^{8}$ and are included in a number of patented formulations for photographic and printing materials. ${ }^{9}$

Bromonitroalkanols are normally obtained by bromination of the corresponding nitroalkanols with bromine, ${ }^{10}$ in a procedure that may lead to double bromination giving 2,2-dibromo-2-nitroalkanols as by-products. 2-Bromo-2nitroalkan-1,3-diols have been prepared by double nitroaldol addition of bromonitromethane to aldehydes under pH-controlled conditions. ${ }^{11}$ On the other hand, controlled mono-addition of bromonitromethane to aldehydes has been achieved under heterogeneous acidic (one example) or basic (two examples) catalysis, ${ }^{12}$ and very recently by NaI catalysis under very mild conditions. ${ }^{13}$ However, despite the effect of the absolute stereochemistry on the biological activity of chiral compounds, a procedure for the synthesis of 2-bromo2-nitroalkan-1-ols in enantiomerically enriched form has not been reported to date, with the only exception of one example of diastereoselective addition of bromonitromethane to a chiral 2-amino aldehyde. ${ }^{13}$

Departament de Química Orgànica, Facultat de Química, Universitat de València, Dr Moliner 50, Burjassot (València), E-46100, Spain. E-mail:jose.r.pedro@uv.es; gonzalo.blay@uv.es;

Fax: + 34 963544328; Tel: + 34963544336

$\dagger$ Electronic supplementary information (ESI) available: Experimental procedures, characterization data and copies of NMR spectra and chromatograms for compounds 4a-t. See DOI: 10.1039/b809739a

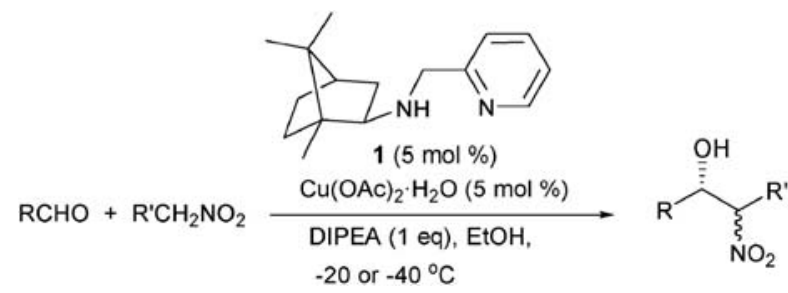

Scheme 1 Nitro-aldol reaction between nitroalkanes and aldehydes catalyzed by copper(II) acetate and amino pyridine ligand $\mathbf{1}$.

Recently our group has developed new ligands for the asymmetric metal-catalyzed Henry (or nitro-aldol) reaction. ${ }^{14}$ We have found that the catalytic system formed by copper(II) acetate and a camphor-derived $C_{1}$-symmetric amino pyridine ligand 1 catalyzes the addition of nitromethane and other nitroalkanes to aliphatic and aromatic aldehydes with very high enantioselectivity, up to $98 \%$ ee, under very advantageous experimental conditions (Scheme 1). ${ }^{15}$ From these results, we envisioned that the reaction between bromonitromethane and aldehydes using this catalytic system could provide the expected 2-bromo-2-nitroalkan-1-ols in highly enantioenriched form.

The reaction between bromonitromethane (3) and benzaldehyde (2a) was used for the optimization process (Scheme 2, $\mathrm{R}=\mathrm{Ph}$ ). Initially, the reaction was carried out under similar conditions to those used in our previous work with nitromethane, which involved the use of 1 eq. of diisopropylethylamine (DIPEA) in ethanol at $-40{ }^{\circ} \mathrm{C}$. We were very pleased to observe that, after $7 \mathrm{~h}$, the reaction was almost completed affording compound 4a as anti : syn $1: 1$ diastereomeric mixture with 67 and $74 \%$ ee, respectively. The enantioselectivity of the reaction was lower than that obtained in the reaction of nitromethane with benzaldehyde $(98 \%$ ee) under identical conditions. ${ }^{15}$ We hypothesized that this lower enantioselectivity may be due to the competitive uncatalyzed addition of the bromonitromethane nitronate which should be present in higher concentration than in the case of nitromethane. As anticipated, a reduction in the amount of base minimized this side reaction and the expected product $\mathbf{4 a}$ was obtained with increased enantioselectivity (Table 1, entries 2-4). The amount

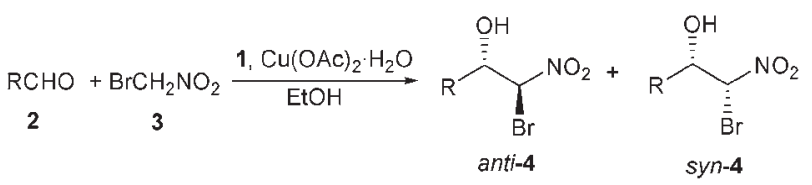

Scheme 2 Catalytic enantioselective synthesis of 2-bromo-2nitroalkan-1-ols by addition of bromonitromethane to aldehydes. 
Table 1 Asymmetric addition of bromonitromethane to benzaldehyde $(\mathrm{R}=\mathrm{Ph})$ catalyzed by copper(II) acetate and ligand $\mathbf{1}$ according to Scheme 2. Optimization ${ }^{a}$

\begin{tabular}{|c|c|c|c|c|c|c|}
\hline Entry & Additive & $T /{ }^{\circ} \mathrm{C}$ & $t / \mathrm{h}$ & $\begin{array}{l}\text { Conv. } \\
(\%)^{b}\end{array}$ & Anti $: s y n^{b}$ & ee $(\%)^{c}$ \\
\hline 1 & DIPEA (1 eq) & -40 & 7 & $>99$ & $52: 48$ & $67 / 74$ \\
\hline 2 & DIPEA $(60 \mathrm{~mol} \%)$ & -40 & 7 & $>99$ & $64: 36$ & $73 / 70$ \\
\hline 3 & DIPEA $(20 \mathrm{~mol} \%)$ & -40 & 7 & $>99$ & $52: 48$ & $77 / 77$ \\
\hline 4 & DIPEA $(10 \mathrm{~mol} \%)$ & -40 & 7 & $>99$ & $42: 58$ & $86 / 93$ \\
\hline 5 & $\mathrm{NaI}(10 \mathrm{~mol} \%)$ & -20 & 40 & $>99$ & $31: 69$ & $89 / 90$ \\
\hline 6 & $\mathrm{CsF}(10 \mathrm{~mol} \%)$ & -20 & 6 & $>90$ & $31: 69$ & $79 / 81$ \\
\hline 7 & - & -40 & 40 & $>99$ & $60: 40$ & $95 / 93$ \\
\hline 8 & - & 0 & 2 & $>99$ & $59: 41$ & $84 / 78$ \\
\hline
\end{tabular}

${ }^{a}$ All experiments were carried out under nitrogen: $0.5 \mathrm{mmol}$ of $\mathbf{2}$, $0.025 \mathrm{mmol}$ of $\mathrm{Cu}(\mathrm{OAc})_{2} \cdot \mathrm{H}_{2} \mathrm{O}, 0.025 \mathrm{mmol}$ of $\mathbf{1}, 5.0 \mathrm{mmol}$ of $\mathbf{3}$ and additive in $2 \mathrm{~mL}$ of EtOH. ${ }^{b}$ Determined by ${ }^{1} \mathrm{H}$ NMR. ${ }^{c}$ Determined by HPLC.

of DIPEA could be decreased to $10 \mathrm{~mol} \%$ with respect to the aldehyde without any noticeable decrease of the reaction rate, the addition product $\mathbf{4 a}$ being obtained in 86 and $93 \%$ ee for the anti and syn isomers, respectively (entry 4). When NaI was used in place of DIPEA, compound $\mathbf{4 a}$ was obtained with similar enantiomeric excesses but with higher diastereoselectivity, although the reaction required more time (entry 5). Similar results were obtained when $\mathrm{CsF}$, with the more basic fluoride ion, was used as the base. Finally, it was observed that the acetate ion of the copper salt was able to promote the reaction without the need for an external base. Under these conditions, compound 4a was obtained as a $6: 4$ anti : syn mixture in $95 / 93 \%$ ee, respectively (entries 7 and 8 ). Note that the reactions without base and with $\mathrm{NaI}$ gave different major diastereomers (entries 5 and 7); however, this was not a general trend (vide infra).

Substrate scope was studied under "base-free" conditions. $\ddagger$ A variety of aromatic and heteroaromatic aldehydes were found to be suitable substrates, ${ }^{16}$ with the reaction providing the expected bromonitroalkanols $\mathbf{4}$ in high to quantitative yields (Tables 1 and 2, entries 1-16). 2-Methoxybenzaldehyde reacted especially fast, indicating a possible chelating effect of the substrate with the catalyst. The reaction products $\mathbf{4}$ were obtained as mixtures of anti and syn diastereomers with moderate to good diastereoselectivities and very high enantiomeric excesses (near or above $90 \%$ ee) for both diastereomers. Only 4-nitrobenzaldehyde (entry 14) gave the condensation product $\mathbf{4 m}$ with low ee. A substituent at the orthoor meta-position favored the syn products (with the exception of 3-methoxybenzaldehyde, entry 8), while para-substituted benzaldehydes gave the anti isomers as the major products. The reaction with 2-chlorobenzaldehyde was also tested with the addition of $10 \mathrm{~mol} \% \mathrm{NaI}$ (entry 5); however an inversion of the diastereoselectivity with respect to the reaction in absence of additives was not observed in this case. Remarkably, the reaction could also be performed with unbranched and even branched or sterically hindered aliphatic aldehydes (entries 17-20). In these cases, the reaction needed to be carried out at higher temperature $\left(0{ }^{\circ} \mathrm{C}\right)$ and the resulting products were obtained in high yield and good enantiomeric excesses, only slightly below the ee values obtained with aromatic aldehydes. Finally, the reaction with the $\alpha, \beta$-unsaturated aldehyde, cinnamaldehyde (2t), afforded exclusively the 1,2-addition product $\mathbf{4 t}$ in almost quantitative
Table 2 Asymmetric addition of bromonitromethane to aldehydes catalyzed by copper(II) acetate and ligand $\mathbf{1}$. Substrate scope ${ }^{a}$

\begin{tabular}{|c|c|c|c|c|c|c|}
\hline Entry & Aldehyde & $T /{ }^{\circ} \mathrm{C}$ & $t / \mathrm{h}$ & $\begin{array}{l}\text { Yield } \\
(\%)^{b}\end{array}$ & anti $: s y n^{c}$ & $\begin{array}{l}\text { ee } \\
\left.{ }^{(\%)}\right)^{d}\end{array}$ \\
\hline 1 & Benzaldehyde (2a) & -40 & 40 & 99 & $60: 40$ & $95 / 93$ \\
\hline 2 & 2-Methylbenzaldehyde (2b) & -40 & 40 & 99 & $16: 84$ & $98 / 96$ \\
\hline 3 & $\begin{array}{l}\text { 2-Methoxybenzaldehyde } \\
\text { (2c) }\end{array}$ & -40 & 4 & 95 & $21: 79$ & $94 / 95$ \\
\hline 4 & 2-Chlorobenzaldehyde (2d) & -40 & 45 & 80 & $13: 87$ & $94 / 97$ \\
\hline $5^{e}$ & 2-Chlorobenzaldehyde (2d) & 0 & 24 & 92 & $15: 85$ & $93 / 88$ \\
\hline 6 & 2-Nitrobenzaldehyde (2e) & -40 & 45 & 86 & $15: 85$ & $88 / 96$ \\
\hline 7 & 3-Methylbenzaldehyde (2f) & -40 & 45 & 99 & $32: 68$ & $94 / 97$ \\
\hline 8 & $\begin{array}{l}\text { 3-Methoxybenzaldehyde } \\
\text { (2g) }\end{array}$ & -40 & 45 & 98 & $61: 39$ & $94 / 94$ \\
\hline 9 & 3-Chlorobenzaldehyde (2h) & -40 & 45 & 97 & $41: 59$ & $94 / \mathrm{nc}$ \\
\hline 10 & zaldehyde (2i) & -40 & 45 & 72 & $40: 60$ & $87 / 94$ \\
\hline 11 & ehyde $(2 \mathbf{j})$ & -40 & 40 & 83 & $70: 30$ & $89 / 92$ \\
\hline 12 & $\begin{array}{l}\text { 4-Methoxybenzaldehyde } \\
\text { (2k) }\end{array}$ & -40 & 45 & 95 & $63: 37$ & $93 / 94$ \\
\hline 13 & 4-Chlorobenzaldehyde (2l) & -40 & 45 & 95 & $69: 31$ & $90 / 90$ \\
\hline 14 & 4-Nitrobenzaldehyde (2m) & -40 & 45 & 85 & $64: 36$ & $44 / 38$ \\
\hline 15 & $\begin{array}{l}\text { Thiophene-2-carbaldehyde } \\
\text { (2n) }\end{array}$ & -40 & 45 & 99 & $36: 64$ & $89 / 95$ \\
\hline 16 & $\begin{array}{l}\text { Thiophene-3-carbaldehyde } \\
\text { (2o) }\end{array}$ & -40 & 45 & 99 & $32: 68$ & $91 / 95$ \\
\hline 17 & Decanal (2p) & 0 & 24 & 95 & & $83 / 91$ \\
\hline 18 & $\begin{array}{l}\text { Dihydrocinnamaldehyde } \\
\text { (2q) }\end{array}$ & 0 & 24 & 99 & $54: 46$ & $87 / 87$ \\
\hline 19 & Isovaleraldehyde (2r) & 0 & 16 & 97 & $57: 43$ & $86 / 92$ \\
\hline 20 & $\begin{array}{l}\text { Cyclohexanecarbaldehyde } \\
(\mathbf{2 s})\end{array}$ & 0 & 16 & 99 & $66: 34$ & $90 / 91$ \\
\hline 21 & Cinnamaldehyde (2t) & -40 & 40 & 99 & $32: 68$ & $81 / 96$ \\
\hline
\end{tabular}

${ }^{a}$ All experiments were carried out under nitrogen: $0.5 \mathrm{mmol}$ of $\mathbf{2}$, $0.025 \mathrm{mmol}$ of $\mathrm{Cu}(\mathrm{OAc})_{2} \cdot \mathrm{H}_{2} \mathrm{O}, 0.025 \mathrm{mmol}$ of $\mathbf{1}, 5.0 \mathrm{mmol}$ of $\mathbf{3}$, in $2 \mathrm{~mL}$ of EtOH. ${ }^{b}$ Isolated yield of $4 .{ }^{c}$ Determined by ${ }^{1} \mathrm{H}$ NMR. ${ }^{d}$ Determined by HPLC. ${ }^{e} 10 \mathrm{~mol} \% \mathrm{NaI}$, conditions as in Table 1 , entry 5 .

yield, good diastereoselectivity and high ee for both diastereomers (entry 21). It should be noted that although a $90 \%$ pure technical bromonitromethane containing $10 \%$ nitromethane was used in all the reactions, no products arising from the addition of nitromethane were observed in the reaction mixtures.

The anti : syn diastereomeric ratio was determined from the integration of the ${ }^{1} \mathrm{H}$ NMR signals for the protons adjacent to the $\mathrm{OH}$ and $\mathrm{NO}_{2}$ groups corresponding to each diastereomer. The coupling constants $(J)$ between these protons appear in the 7.5-9.0 Hz range for the anti isomer and in the $2.1-5.4 \mathrm{~Hz}$ range for the syn isomer. These $J$ values are in good agreement with those calculated from the dihedral angles $\left(\sim 180^{\circ}\right.$ for the anti and $\sim 45^{\circ}$ for the syn isomers) between $\mathrm{H} 1$ and $\mathrm{H} 2$ in the lower-energy conformation, ${ }^{17}$ and with those observed for related 2-alky-2-nitroalkan-1-ols. ${ }^{3,15}$

The absolute stereochemistry of bromonitroalkanol 4a was determined by chemical conversion into the known compound (S)-5, via reductive dehalogenation (Scheme 3). Treatment of a 65 : 35 anti : syn mixture of $\mathbf{4 a}(79 \%$ ee for the anti isomer, $80 \%$ ee for the syn isomer) with $\mathrm{Bu}_{3} \mathrm{SnH}$ in the presence of AIBN $^{18}$ afforded $(S)-5$ in almost quantitative yield and $80 \%$ ee, ${ }^{19}$ showing that the configuration of the carbon atom bearing the hydroxyl group was $S$ in both the anti and syn diastereomers. Similar results were obtained with compounds $\mathbf{4 b}, \mathbf{f}, \mathbf{j}, \mathbf{s}$ indicating the existence of a common stereochemical 


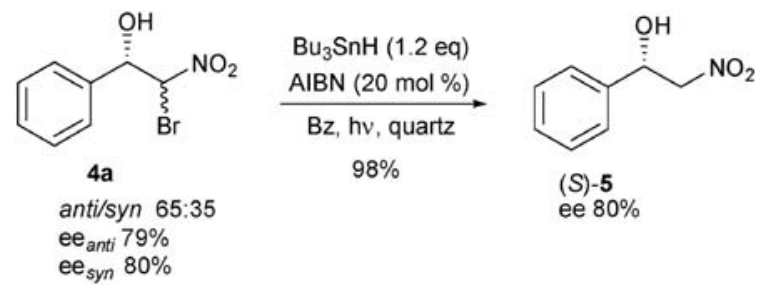

Scheme 3 Determination of the absolute stereochemistry of compound 4a.

pathway regardless of the location of the substituent on the aromatic ring or the aromatic/aliphatic nature of the aldehyde. The stereochemistry for the rest of compounds $\mathbf{4}$ was assigned as $1 S$ on the assumption of this uniform reaction mechanism. The absolute stereochemistry of compounds $\mathbf{4}$ is in agreement with the preferential approach of the nitronate from the $R e$ face of the aldehyde carbonyl group according to our previously proposed mechanism. ${ }^{15}$

In summary, we have developed the first general procedure for the enantioselective synthesis of 2-bromo-2-nitroalkan-1-ols, which are compounds with important practical applications. The procedure involves the Henry reaction between bromonitromethane and aldehydes in the presence of a low load $(5 \mathrm{~mol} \%)$ of a catalytic system, recently developed in our laboratory, that uses copper(II) acetate and a readily available camphorderived amino pyridine ligand. The reaction is general in scope providing the expected products with high to quantitative yields and good to excellent enantioselectivities with a broad range of aromatic, heteroaromatic, aliphatic and unsaturated aldehydes.

The authors thank the Ministerio de Educación y Ciencia and FEDER (Grant CTQ 2006-14199/BQU) for financial support. V. H.-O. thanks the Universitat de València for a pre-doctoral grant (V Segles program).

\section{Notes and references}

$\ddagger$ A solution of amino pyridine $\mathbf{1}(6.7 \mathrm{mg}, 0.025 \mathrm{mmol})$ in absolute ethanol $(2 \mathrm{~mL})$ was added to $\mathrm{Cu}(\mathrm{OAc})_{2} \cdot \mathrm{H}_{2} \mathrm{O}(5.0 \mathrm{mg}, 0.025 \mathrm{mmol})$ contained in a Schlenk tube under nitrogen. The mixture was stirred for $1 \mathrm{~h}$ at room temperature until the formation of a deep blue solution. Benzaldehyde (2a, $53 \mu \mathrm{L}, 0.5 \mathrm{mmol})$ was added and the reaction flask introduced in a bath at $-40{ }^{\circ} \mathrm{C}$. After $5 \mathrm{~min}, 90 \%$ pure technical bromonitromethane $(3,0.39 \mathrm{~mL}, 5 \mathrm{mmol})$ was added and the reaction mixture was stirred for $40 \mathrm{~h}$. The mixture was treated with $1 \mathrm{M}$ aqueous $\mathrm{HCl}(15 \mathrm{~mL})$ and extracted with dichloromethane $(3 \times 15 \mathrm{~mL})$. The organic layer was washed with brine $(20 \mathrm{~mL})$, dried over $\mathrm{MgSO}_{4}$ and concentrated under reduced pressure to give $\mathbf{4 a}$ (121 mg, 99\%).

1 M. Shibasaki and H. Göger, in Comprehensive Asymmetric Catalysis, ed. E. N. Jacobsen, A. Pfaltz and H. Yamamoto, Springer, Berlin, 1999, vol. 3, pp. 1075-1090; M. Shibashaki, H. Göger and M. Kanai, in Comprehensive Asymmetric Catalysis, ed. E. N. Jacobsen, A. Pfaltz and H. Yamamoto, Springer, Heidelberg, 2004, supplement 1, pp. 131-133; C. Palomo, M. Oiarbide and A. Mielgo, Angew. Chem., Int. Ed., 2004, 43, 5442; J. Boruwa, N. Gogoi, P. P. Saikia and N. C. Barua, Tetrahedron: Asymmetry, 2006, 17, 3315; C. Palomo, M. Oiarbide and A. Laso, Eur. J. Org. Chem., 2007, 2561

2 B. M. Trost and V. S. C. Yeh, Angew. Chem., Int. Ed., 2002, 41, 861; D. A. Evans, D. Seidel, M. Rueping, H. W. Lam, J. T. Shaw and C. W. Downey, J. Am. Chem. Soc., 2003, 125, 12692; Y. Kogami, T. Nakajima, T. Ikeno and T. Yamada, Synthesis, 2004, 1947; C. Palomo, M. Oiarbide and A. Laso, Angew. Chem., Int. Ed., 2005, 44, 3881; B. M. Choudary, K. V. S. Ranganath, U. Pal, M. L. Kantam and B. Sreedhar, J. Am. Chem. Soc., 2005, 127, 13167; H. Maheswaran, K. L. Prasant, G. G. Krishna, K. Ravikumar, B. Sridhar and M. L. Kantam, Chem. Commun., 2006, 4066; Y. Sohtome, Y. Hashimoto and K. Nagasawa, Eur. J. Org. Chem., 2006, 2894; H. Li, B. Wang and L. Deng, J. Am. Chem. Soc., 2006, 128, 732; M. Marcelli, R. N. S. van der Haas, J. van Maarseveen and H. Hiemstra, Angew. Chem., Int. Ed., 2006, 45, 929; K. Ma and J. You, Chem.-Eur. J., 2007, 13, 1863; M. Bandini, F. Piccinelli, S. Tommasi, A. Umani-Ronchi and C. Ventrici, Chem. Commun., 2007, 616; D. Uraguchi, S. Sakaki and T. Ooi, J. Am. Chem. Soc., 2007, 129, 12392; B. Qin, X. Xiao, X. Liu, J. Huang, Y. Wen and X. Feng, J. Org. Chem., 2007, 72, 9323.

3 H. Sasai, T. Suzuki, S. Arai, T. Arai and M. Shibasaki, J. Am. Chem. Soc., 1992, 114, 4418; H. Sasai, T. Tokunaga, S. Watanabe, T. Suzuki, N. Itoh and M. Shibasaki, J. Org. Chem., 1995, 60, 7388; T. Ooi, K. Doda and K. Maruoka, J. Am. Chem. Soc., 2003, 125, 2054; T. Purkarthofer, K. Gruber, M. Gruber-Khadjawi, K. Waich, W. Skrank, D. Mink and H. Griengl, Angew. Chem., Int. Ed., 2006, 45, 3454; Y. Xiong, F. Wang, X. Huang, Y. Wen and X. Feng, Chem.-Eur. J., 2007, 13, 829; T. Arai, M. Watanabe and A. Yanagisawa, Org. Lett., 2007, 9, 3595.

4 N. G. Clark, B. Croshaw, B. E. Leggetter, D. F. Spooner and F. David, J. Med. Chem., 1974, 17, 977.

5 Y. Konagai, K. Konya, M. Muto and K. Takita, Jpn. Pat., JP 50117933, 1975; W. F. McCoy, S. Thornburgh, World Pat., WO 8911793, 1989.

6 J. M. McLennan, K. D. Brunt and W. G. Guthrie, Br. Pat., GB 2183477, 1987.

7 M. Watanabe and T. Fukuda, Jpn. Pat., JP 01013001, 1989.

8 J. Norden, H. Aigner, F. Schindler and R. Samblebe, Ger. Pat., DE 322724, 1985; H. Lehmann, M. Gross, A. Jumar, P. Held, A. Rehnig and G. Tschampel, Ger. Pat., DD 133885, 1979.

9 T. Yamada, Jpn Pat., JP 8134371, 1996; S. Hirabayashi, Jpn. Pat., JP 07140620, 1995; T. Marui, Jpn. Pat., JP 03100645, 1991; H. Sakata, T. Nagashima and T. Arai, Jpn. Pat., JP 03038634, 1991; J. Fukawa and T. Habu, Eur. Pat., EP 356801, 1990; Eur. Pat., EP 342987, 1989; K. Mine, Y. Kobayashi, Y. Kawaguchi and S. Aoki, Jpn. Pat., JP 61055173, 1986.

10 W. Stelmachowski, E. Utecht, J. Wasowska and K. Florczak, Polish Pat., PL 100819, 1979; D. Sato, Y. Motoyama and T. Shoji, Jpn. Pat., JP 52003011, 1977; R. Wessendorf, Ger. Pat., DE 1954173, 1971.

11 J. E. Williams and S. Thornburgh, World Pat., WO 9211229, 1992K. Kojima, Jpn. Pat., JP 54141738, 1979.

12 R. Ballini, G. Bosica and M. Parrini, Chem. Lett., 1999, 1105; R. Ballini, G. Bosica and P. Forconi, Tetrahedron, 1996, 52, 1677.

13 J. M. Concellon, H. Rodriguez-Solla, C. Concellon, S. GarciaGranda and M. R. Diaz, Org. Lett., 2006, 8, 5979.

14 G. Blay, E. Climent, I. Fernández, V. Hernández-Olmos and J. R. Pedro, Tetrahedron: Asymmetry, 2006, 17, 2046; G. Blay, E. Climent, I. Fernández, V. Hernández-Olmos and J. R. Pedro, Tetrahedron: Asymmetry, 2007, 18, 1603; G. Blay, V. HernándezOlmos and J. R. Pedro, Org. Biomol. Chem., 2008, 6, 468.

15 G. Blay, L. R. Domingo, V. Hernández-Olmos and J. R. Pedro, Chem.-Eur. J., 2008, 14, 4725.

16 Ketones such as acetophenone do not react under this experimental protocol.

17 Conformational energies were minimized and calculated using the MM2 force field. Theoretical $J$ values were calculated according to: C. A. G. Haasmot, F. A. A. M. DeLeew and C. Altona, Tetrahedron, 1980, 36, 2783; K. G. R. Pachler, J. Chem. Soc., Perkin Trans. 2, 1972, 1936.

18 W. R. Bowman, D. Crosby and P. J. Westlake, J. Chem. Soc., Perkin Trans. 2, 1991, 73.

19 The $(S)$ configuration for compound $\mathbf{5}$ was assigned by comparison of the HPLC retention times with those of an authentical sample of (S)-5; see ref. 13. 